\title{
Role of Philosophy in Human Development in Nigeria
}

\author{
Jude Chinweuba Asike \\ http://dx.doi./org/10.4314/ujah.v18i2.3
}

\begin{abstract}
It is indeed absurd to talk about development or impose on a human race a civilization without reference to Philosophy. Philosophy is a living subject which embraces all dialectical interpretations of life changes in society. It gives the hermeneutics understanding of reality by acting as a means to an end, through the interpretations of logical relations, ethical issues of categorical imperatives and methodological principles and concepts in our lives given situations. This paper therefore, intends to outline the issue of Philosophical importance to human development. The idea of development in the light of Philosophical postulations, ethical precision and statistics are required for human and scientific development. Philosophy in this perspective is the form and abstraction or the orientation man uses to interpret his world view. It has helped in the concept of human development, to a great deal of being in the epics of the humanitarian paradigm. Philosophy could be a genuine supporting tool for a harmonious existentialism in Nigeria, through proper restructuring of the polity, educational system, and judicial interpretations on the areas of retributive and distributive justice.
\end{abstract}

\section{Introduction}

This paper tries to highlight the provocative and unique issue in philosophy concerning the nature of human development. In Nigeria, a quite a number of philosophical principles are generally utilized in the promotion of human development. The 
philosophical issues of consideration are vital process in the developmental process, and they offer a universal blueprint for all sets of functional relations and human activities in Nigeria. According to Onwuama, he views philosophy as:

A critical, reflective and unbiased investigation on development aimed at providing principles, theories for development. Philosophical issues for development refer to those areas and problems of development that are reserved exclusively for philosophical clarifications and hermeneutics (Onwuama, 2012:167).

Remarkably, philosophy is a determination for the hermeneutics understanding of reality. It is a purposive goal oriented discipline aimed at liberating man from the shackles of ignorance, for sustainability of human existentialism. By understanding the construction of the development era in $21^{\text {st }}$ century, the attention of philosophy has changed from the conquest of truth to the principles of development. These trends involve new discourses and new institutional developments strategy, with a deep-rooted contention over the shape of the emerging order. Thus, "the aim of philosophy is to provide an account of nature and methodology of development and to understand the place of development in people's lives" (Onwuama, 2012:168).

Lately however, at the onset of this $21^{\text {st }}$ century, philosophy became a very latent force in so many areas of human development. It is relevant in the area of education and in formulation of public policy agenda, through its normative value questions, predictive analytics, political consulting, and conflict 
management. All the above factors are not without the ambiance of the philosophical principles and/or theory of development.

Philosophy generally, is construed identical with the concept of development. It is aimed with proffering solutions for human welfare and understanding of reality. It is critical attitude and a reflection towards the problems of human existence. According to Nnamdi (2011:85) in his emphasis on the definition of philosophy, he asserts that:

philosophy is a method of distinguishing fact from fallacies, sifting truth as sacrosanct... it is a method of securitizing our otherwise unexamined beliefs and practices in order to purge them of falsehood and error.

By and large, one will definitely come to conclusion that philosophy guides our behavior outlook into genuine living harmoniously in the society, through the qualitative and quantitative processes in our existence.

\section{Philosophy and Development - A Reconsideration}

The relationship between philosophy and development needs to be examined. Perhaps the chief difference between talking about philosophical ideas and developmental ideas actually are within the scope of philosophy. Unlike the sciences, philosophy does not discover new empirical facts, but instead reflects on the facts we already familiar with, to see what the lead to and how they all hang together. Philosophical thinking includes assessment of terms, evaluation of logical principles of reasoning, willingness to make a refined distinction between right and wrong, deduction and induction, faith and reason, fact and fallacy, knowledge and belief 
and so forth. Philosophy addresses the normative issues in more profound manner of human understanding. It is a critical inquiry into the understanding of reality by reflecting and conducting an investigation into the problems of human existence, in areas of justice, happiness, truth, God, beauty, death, good and evil, morality etc.

Thus, in considerable extent, within the scope of this discussion, we need to appreciate the fact that they philosophers have responsibility to influence the direction of the society, to influence it positively in our lives. In other words, it is the duty of philosophy to evaluate the nature of a society, to determine the right values in the society. Thus, in this direction, a philosophical framework must be able to manage inequality carefully within the concept of justice. A philosopher must know what kind of society we need. What kind of political institution that will be good for a multi-cultural, multi-ethnic society like Nigeria. If we fail to ascertain the kind of society, then our discussions on the process of philosophizing for proper developmental process would be meaningless. It will turn to be exercise in futility. As a philosopher, we need to have a long view of the society, to know where we are, what we have achieved and what to achieve; and from there make inferences about the future.

However, in relating this argument carefully to the socio-political and economic situation in Nigeria, the question now will lead to the characterization of national transformational agenda in Nigeria. How can we talk about development when we are still in the Hobbesian state of nature? A nation state must be well structured, organized and shall be guarded by some procedural rule of law controlling and regulating the excesses of the civil society. A state 
cannot exist in a vacuum, it is built by the members of the society who make up the state; and a state cannot equally be developed without the people who make-up the state.

In relating this to the Nigerian situation, Claude Ake emphasizes that a state is an embodiment of structure; a state is not only in the realm of economic growth and industrialization, but also within the ambiance of social, economic, and technological transformation. It is a process in which the people are full incharge of their lives, in transforming themselves into becoming fuller, stronger, better and bigger in their environment.

This scenario of sustainability and reliance as opined by Ake, is of course very antithetical to the classical economics, which sees development in the sense of per capita income or economic growth. Development is the socio-political and economic wellbeing of the people. This can be discussed on the basis of a state structure. A state with a proper democratic principles and leadership is in process of an authentic development, which critically accompany all its social institutions, economic structures, and educational training into different philosophical goals or agenda. Philosophy therefore, is a set of idealistic goal, the pivotal force, or framework for the national policy formulation and evaluation of public policy. Nigeria for example, is organized in accordance with the principles of federalism, separation of powers, check and balances, popular sovereignty, limited government, majority rule and minority right. Thus, under these factors, Nigeria should be guided by a positive philosophy that will transcend its present state of development. It must be critically endogenous, by making the people to be in-charge of their lives through better distribution of economic resources, protection of life and property, 
provision of security, justice, education, and welfare to the people. This elucidates the criteria of good governance and human development.

Taking this argument further, in a concrete term on the position of a state structure, one will definitely know that in Nigeria, there is no real sense of a humanitarian paradigm. The government has not yet been committed to the real sense of assisting the people in areas of health, education, environment, security, roads etc. The purpose of a good government is all about engendering happiness to the people through the systematic entrenchment of its policies to alleviate the suffering of its citizens; by creating tangible things that make lives easier and free, in order to build a prosperous future for them for continuity of life in their environment.

On the level of this paradigm, let us rewind to recall the manner of the Nigerian state, which is still in a kind of survival of fittest syndrome or a kind of Hobbesian state of nature, where there is no real purpose of development initiatives, that will engender confidence to the people. In Nigeria, there is no real development on the part of the people, this is because, Nigeria is a place where everybody knows that a greater number of people are not educated, that many number of people are not going to school; that many people are living below the subsistence level. Nigeria is also, a place that there is insecurity, the helplessness of the government officials and lack of unity in the continuation of government policies by the successive government in power.

Remarkably, it is upon these highlights that there must be a need for a proper philosophical framework for a genuine development in Nigeria. Nigeria as a state under this condition of anarchy and 
anomaly requires the positive use of philosophy in remodeling the state. Philosophy could be a genuine supporting tool for the restructuring the polity, its education system, judiciary, health care system, environmental cleaning, security etc.

Philosophy will help in bringing out all the trajectories of human happiness and rationalism of individuals and national development; through proper elevation of the GDP, GMP and per capita income. Philosophy will help the state in public policy formulation, through its critical and reflective methods; empirical propositional hermeneutics; and normative theories of analysis. Philosophical studies and research is a must for social, economic, political and technological advancement of any nation. It is necessarily important in the national development in Nigeria. Thus, it is on a related note, that Nnamdi asserts that:

When we talk of national development, we have to remind ourselves that the nation is only real and concrete in terms of people that constitute it... development is people centered, it means that the people that make up the nation, the individual men and women, are both the agents and the beneficiaries of development... The role of philosophy therefore is in the molding the character of individuals (Nnamdi, 2011:85)

Development is a process of transformational agenda. It is not purely materialistic but happens within the context of a people in relation to the level of growth and progression of individual members of a society. Its real essence is on man in a proper way to provide a humanitarian paradigm "which bring about marked 
improvement in the standard of living of the people" (Anozie, 2006:160). In the same way, Offiong (190:21) states that:

It involves a structural transformation of the economy, society politics and culture the satellite that permits the self-generating and self-perpetuating use of the people's potentials.

On a related note, Efemini, further provides us with a transformed framework for interpreting our basic experiences on the subject matter. He remarkably asserts that, "Development is here understood as the quantitative and qualitative improvement in the material, emotional, and spiritual conditions of human existence" (Efemini, 2010:1)

However, this analysis grasps an essential truth that development is a systematic entrenchment of values in both qualitative and quantitative aspect of human life. It is materially, emotionally and spiritually driven as a value within a state that goes beyond the evolutionary perspective. It is inevitable march of progress in every culture. Development is not organized around the competing theories of social-change, nor does it adhere to a simple, allencompassing perspective. Rather, the narrative retraces the concept of development as an increasingly global enterprise that liberates the people through the promotion of a general welfare in the provision of security, shelter, good health and proper democratic governance.

Considering this, Nnamdi asserts that it is "through the wisdom of philosophy that man is able to reflect on his personal life in search of real self, and the meaning of life, he is living" (Nnamdi, 2011:85). Philosophy is a systematic and comprehensive study that 
centers on meaning, interpretation and evaluations of logical relations. According to Socrates, "an unexamined life is not worth living", and in consideration to this, man should know himself. He should explore a better way of improving his life in environment. Thus philosophy for this reason is without a doubt important for human development. It concerns with values, goals and human aspirations for development of human society. It helps in understanding the meaning of development and genuine level of its impact to human development.

Under this category of paradigm, the subject matter of philosophical studies have different outlook in human development process:

First, it has a great impact to social change. It helps man to classify the sets of social change into different categories of purposes and functions. We do not know what a thing is until we classify it into a meaningful context, and to recognize a class is to recognize the unit of essential attributes in a multiplicity of individual instances. Philosophy therefore helps in the classification, quantitative measurement, and hypothesis, which are solely based on the assumption of the development of science.

Secondly, philosophy involves in the political spheres of human existentialism, through genuine democratic process of good politics. The purpose of politics is for good and happy life in a state. Thirdly, philosophy creates social stability and cohesion for proper learning and human education; and finally, it is religious. It establishes man's intentional phenomenology to the understanding of the transcendent. Philosophy justifies the importance of religion 
to man, but with clarity of purpose by sifting facts from fallacies; and truth from falsehood within the realm of culture(s).

\section{Development and Transformation in Nigeria}

The task of a genuine philosophical inquiry is important for human development in Nigeria, because it will assist us to a more profound understanding of the society, to a better human development. In 1960 at the inception of Nigerian independence, it inherited what were actually four economies, the traditional African indigenous economy, the modern, the Christian religious economic tradition, and the Islamic - religious traditions.

\section{The Nigerian Economy}

The traditional economy is characterized by a large of rural farming that is based on subsistence level with little opportunity to accumulate savings for investment and innovation. This condition does not permit the acquisition for a self-reliance and sustainability of an independent state.

The modern economy could not thrive adequately due to the constant fracture line in area of lack of national integration from variance of ethnocentrism, occurring within the multi-secular democracy in Nigeria. It brought a lot of setbacks to the postcolonial administration in Nigeria. Ethnocentrism, corruption, tribalism, nepotism etc., are the misgiven of the negative philosophy of culture in Nigeria. It reduces the tenacity of the objects of challenging intellectual experiences of development in Nigeria; which could have become the philosophical goals for human and national development in Nigeria. 
Christian and Islamic religious ideologies are the next sets of issues in socio-political economy that really brought some setbacks in the development process in Nigeria. Actually, it could have been the other way round in promoting economic growth in Nigeria, but the scenario has brought the condition of conflicts to the state. Religion certainly, is an organ of economic and political development of many nations in the world. The Buddhist religion has helped in transformation of the economic development of Japan, Hindus is for India economic development, Confucianism has help a great deal in transforming the Chinese economy, Christianity via the supports of Greek philosophy has helped in the political and economic development of the West. In Nigeria for example, Ubuntu, could have been the ground for the Nigerian national development in Africa. This was not so, because of the conditions and circumstances of the African state, occupation by foreign cultures; the Islamic - Arabic traditions, and EuroChristian traditions in Nigerian state.

Again, going contrary to this argument, in purely religious state homogeneity, like the state of Japan - Buddhism, India Hinduism, China - Confucianism etc., the distinctive policies of state are homogeneously based on the state religion. The purposive actions, the decisions, goals, visions and missions are the same. They are within the ambiances of the same economics and sociopolitical ethics. More so, as seen in this light, as might be observed in a country like Nigeria, with pluralist approaches in making of public policy, these different indigenous organizations have different penultimate goals or agenda in enforcement of their doctrines. Some religious agendas are different from the state policies. A notable example, in this direction is the outright rejection of the principles of modernity by the Islamic religious 
sect of Boko Haram. It had become equally clear that their pronouncement on the hermeneutics of Sharia have placed them outside the political realities of public policy in Nigeria. Their strong, moral state which says that western education is evil is an aberration to the state of Nigerian secularism.

Remarkably, the ethical orientations of religion should be towards justice for all, truth, respect for human rights and love for others. Religion, "strive in various ways to promote good health, to conduct medical institutions, to defend the rights of children, women, and oppressed people, and to take practical initiatives in the educational field" (Arinze, 2012:114).

This invariably means that the state and religions are within the same parlance of human and national development. They are not replacing or competing with the government, rather they are agents of human development, to contribute to peace from the religious and spiritual dimensions. Thus, it is the duty of the religionists to remind to the people that peace is a necessary requirement for human development.

\section{The Challenging Blueprint and Economic Record}

In 1960, at the inception of Nigeria independence, there was a timetable for economic development, but after six year of independence, it came to a halt, due to the incessant coupe d'état in Nigeria. The national development plan and philosophical initiatives for self-sufficient industrial, system became blind due to the politics arising from ethnicity and religious conflicts. The nation at this time were in the state of anomaly, no real development plans and economic initiatives for sustainable development in Nigeria. 
The economic development in Nigeria could be successful in the long run only if it avoids the religious and socio-political cleavages, inequalities in distribution of resources, and corruptions in Nigeria.

Agricultural investments would have been highly encouraged to sustain the timing population. Moreso, the sales of petroleum hydrocarbon energy would have helped in the diversification of the economy, and investment purpose in Nigeria. The construction of refineries to join in the sales of refined products, as being part of economic globalization of the $21^{\text {st }}$ century, would have been the major economic breakthrough in Nigeria. Thus, the yearnings of these economic development models have been fallacious, due to the lack of philosophical principles, theories, generation of tools, and ideas for developmental concepts in Nigeria. Philosophy could have provided the account of the nature and methodology of these kinds of development in Nigeria. It would have given the much needed lack of unity in Nigeria, through proper philosophical orientations and national ethics in the constitution.

Moreso, there are conditions of enclave production in Nigeria and the economy is not diversified. The economy is wholly based in the enclave production of export of primary products that are generated in small areas. There was no diversification of the economy; lands were not granted for other uses other than the subsistence farming, for agricultural product for export. Subsequently, the discovery of large oil deposits had changed the equation. Thus, this situation took over every aspect of the economy, that they could not even diversified the institutional production, but dwell mostly in the sales of crude oil (primary 
product). The diversification of the economy in other important areas, have not been done equally in Nigeria. In this $21^{\text {st }}$ century era of globalization, Nigeria would have been very relevant in global economic hierarchy; if it has been diversified into other areas of the economy. Again, they did not utilize the importance of the huge money accrued from the sales of the crude oil to invest profusely in the building of modular refineries across the nation.

Remarkably, this condition would have given them the stance of not importing the refined product from abroad. Within this conditional economy, if a nation produces and consume, that will be a mark of self-reliance and sustainability, but if they produce, consume and export, it means that they are highly developed, and could be able to maintain the lives of its citizens through better education, health, environment, security and proper democratic process.

\section{The Impact of Philosophy on Human Development in Nigeria}

Nigeria is multi-ethnic, multi-cultural and multi-lingual nation. It has about 250 ethnic groups, with several languages and dialects. There is no nation without a problem, but the problem drastically disturbing Nigeria is the problem of lack of national integration. It has been the cause of conflict in Nigeria. The ethnic relation in Nigeria is fragmented; there is no collaboration in view of economic and political relationship. It is a nation characterized with division, hatred and rancor and philosophy is needed to remove the atavistic tendencies in the culture. It will help to reorient the people into living together as a nation. A nation without philosophy - is doom to fail, because it helps to educate the people into knowing the truth, being rational and constructive. 
In corroboration with this, Ladriere (1992:17) has this to say:

Philosophy is the reflection of experience upon itself, endeavoring to grasp its own constitutions and its own significance and to follow as far as possible the threads of implication which connect human experience with its most remote conditions of possibility... The real content of experience is revealed by the actions and the works in which the life of consciousness manifest itself.

Here, philosophy is seen as hermeneutic understanding of realities, as an epistemological tool of bridging the hiatus between cultures. It is an intellectual discipline which will be used to remove all the atavistic inhibitions in our traditions. Philosophical understandings will bring the rational thought that there is no essential difference among all the ethnic groups. It will enhance them into harmoniously living their lives in the society, by enabling them to fit in well in interpersonal, inter-ethnic and international relationships.

More so, the idea of human nature and rights of man has been a philosophical issue. Scholars like St. Thomas Aquinas, Rousseau, Hobbes, John Locke, John Rawls, and Robert Nozick have done a great job on the concept of human rights.

The point being made here is that the study of philosophy will help in the judicial interpretation of distributive justice in Nigeria. There is an extensive theoretical philosophy that challenges the essence of distributive justice in Nigeria. A long-standing line of "quota system" interpretation portrays inequality as a structural component of conflict in Nigeria. Thus, philosophy will bring the 
clarifications of meaning into a better understanding of distribution, by given a legitimate right of distribution of the national resources equitably.

According to Robert Nozick on the liberty of rights, he stated it in this manner:

Let us call a principle of distribution pattern and nonpattern principle of justice or set of characteristics which specifies how the distribution is to be achieved. A principle of distribution pattern, if it specifies that a distribution is to vary with some natural dimension, it must weigh the sum of natural dimensions, or lexicographic ordering of natural dimension. (Robert Nozick, 974:156).

Nozick, finds any patterned principle objectionable, because it acts as an infringement on individual liberty. According to Nozick, individual must voluntarily transfer their resources, and any infringement on that by the government in a way of taxation, is an unjust act and a violation of individual rights for ownership of property.

This indication has been one of the causes of conflict in Niger Delta area of Nigeria. It leads to the issue of resource control for equitable distribution of resources in Nigeria. Equity Principle in the field of distributive justice would be very sacrosanct in distribution of economic resource in Nigeria. It is a philosophical theory of distribution without hatred and rancor. It supports the distribution of benefits in proportion to what the individual contributed. It increases productivity and growth of economy in relation to individual and state. 
Philosophy has a major role to play in the resolution of religious conflict in Nigeria. Philosophy involves the clarification of concepts and understanding of life. It removes the ambiguity and vagueness in our ontology. Thus, with this in question, it will find reason in revealing the ambiguity in religious doctrines which may be harmful to the society. Philosophy therefore is a rational scrutiny of religious claims. It critically examines the exigency of overzealous religious inhibitions in human existence. Philosophy is important in molding of individual character. It is a normative inquiry on "what is", and about "what ought to be" in our moral attitudes.

It transforms our values into rational - altruistic benefits to man. In its entirety, its evaluative purposes and meanings are wholly based in the essence of humanitarian paradigm to better the environment and the people. In practice, a nation, for example like Nigeria should borrow a leaf from this to better the life of their citizens.

Stated most simply, philosophy has formulated the survey of controversial and pressing issues in public policy. I have no doubt that philosophy is now a benchmark for any developmental process in Nigeria, as well as offer a substantial contribution to policy analysis with the analytic approaches in the field, such has ethical evaluation of the public policy issues, criteria of justice and trust in society. Hence Philosophy is a great impact to the hard reality of policy making in the national constitution in Nigeria, which are within the ambits of law in the following factors:

(1) The Preservation of Life of Individual in the State

(2) The Preservation of Individual Autonomy

(3) Fair Treatment of Citizens. 
The Philosophical justifications of public policy analysis are mostly by utilitarianism, with action being justified as producing the greatest net benefit for the society as a whole. Thus, in Nigeria, it has helped in the formulation and evaluation of public policy agenda, through promotion of 'quota system' to carry everybody along in a multi-cultural, multi-ethic, multilingual, and multisecular nation of Nigeria.

\section{Conclusion}

This paper supported the claim that philosophy is important to human development in Nigeria. Here in the world, we tried to justify the role played by philosophy in the development process through right education, inculcating of good moral up-bringing, clarifications of the ambiguity in the scope of distribution of resources, and to be resolved by the adoption of the principle of equity in the theory of distributive justice.

Thus, in all spheres of inquiries into the nature and epistemological experience to knowledge, philosophy is a weapon which can aid our adjustment to the advancement of human development.

\section{Jude Chinweuba Asike}

University of Port Harcourt

Port Harcourt

asikejude@yahoo.com 


\section{References}

Efemini O.A, Claude Ake. Philosophy of Development: Implication for Nigeria, Port Harcourt: University of Port Harcourt Press 2010.

Ladriere, K. African Symbols: Hermeneutic of Destiny. New York: Peter Lang Press.

Landsman, C., Philosophy: Introduction to the Central, New York:

CBS College Publishers, Rinehart and Winston Drydn Press, 1985

Nnamdi B.S, Selected Themes in Logic and Philosophy, Port Harcourt, Nigeria: Univ. of Port Harcourt Press, 2011.

Nozick R, Anarchy, State and Utopia, New York: Basic Books, 1974.

Offiong D.A, Imperialism and Dependency, Enugu: Fourth Dimension Publishers, 1980.

Onwuama, E. Understanding philosophy In Oloidi Jumoke (Ed.), Fundamentals of Philosophy, Logic and Issues in Human Existence, Enugu Kriscento Publishers. 2011.

Rodney, W., How Europe Underdeveloped Africa, Washington D.C.: Howard Univ. Press.

Wheelwright, The Way of Philosophy. New York: Odyssey Press, 1960. 